\title{
Prediction of total phenolics, anthocyanins and antioxidant capacity of blackberry (Rubus sp.), blueberry (Vaccinium sp.) and jaboticaba (Plinia cauliflora (Mart.) Kausel) skin using colorimetric parameters
}

\author{
Thaís Caroline Buttow RIGOLON ${ }^{1 *}$ (D), Frederico Augusto Ribeiro de BARROS ${ }^{1}$, Érica Nascif Rufino VIEIRA ${ }^{1}$, \\ Paulo César STRINGHETA ${ }^{1}$
}

\begin{abstract}
The food industry should have methods that allow identifying bioactive compounds quickly, efficiently and at low cost. The objective of this research was to obtain mathematical models for predicting the amount of total phenolics, anthocyanins and antioxidant capacity of blackberry, blueberry and jaboticaba skin, based on colorimetric parameters $\left(\mathrm{L}^{\star}, \mathrm{a}^{\star}, \mathrm{b}^{\star}, \mathrm{C}^{\star}\right.$ and $\left.\mathrm{h}^{\star}\right)$. All analyses were done in the phenolic extracts obtained from these fruits. The mathematical models were obtained through multiple linear regression using the stepwise method. The significant correlation between the colorimetric parameters and chemical analyses resulted in models with a high predictive ability (high $\mathrm{r}^{2}$ ), such as in the determination of the contents of anthocyanins $\left(r^{2}=0.99\right)$, total phenolics $\left(r^{2}=0.86\right)$ and for the antioxidant capacity $\left(r^{2}=0.99\right)$. Thus, the prediction of levels of these bioactives compound, using colorimetric parameters, is very promising for cost and time savings.
\end{abstract}

Keywords: bioactive compounds; polyphenols; color; pigments.

Practical Application: Fruit characterization in relation to their bioactive compound content using prediction mathematical models.

\section{Introduction}

The antioxidant capacity of fruits is primarily determined by the phenolic compounds present, which contribute to the prevention of oxidative stress and the inhibition of some diseases and inflammatory processes (Rocha et al., 2011; Sousa et al., 2011). Blueberries, blackberries and the jaboticaba skin present high contents of phenolic compounds, such as anthocyanins (Barba et al., 2013; Bowen-Forbes et al., 2010; Silva et al., 2014).

The most common methods used to analyse these compounds are the spectroscopic and $\mathrm{pH}$-differential procedures for determining total anthocyanins, Folin-Ciocalteau for quantifying the phenolic compounds, and the 2,2'-azinobis-3-ethyl-benzothiazoline-6sulphonated (ABTS), 2,2-diphenyl-1-picrylhydrazyl (DPPH) and ferric reducing antioxidant power (FRAP) for determining the antioxidant capacity. Based on this, several studies have been carried out with the objective of correlating complex analysis methods, such as those described above, to simpler ones, such as colorimetry, and infrared, near-infrared and resonance spectroscopy (Ekici et al., 2014; Hosu et al., 2014; Pace et al., 2013).

Colorimetry is a quick and simple analysis technique since it does not use reagents and can be performed directly. It uses chromameters that can be portable and the measured values, according to the chosen system (CIE, CIELAB or CIELCH), can be translated into physical changes, like luminosity, color intensity and hue (Queiroz, 2015).

Facilitating the analyses related to total phenolics, anthocyanins and antioxidant capacity by developing rapid and economical techniques has become a priority in order to meet the demands of quality control of fruits in the industry and in research related to genetic improvement. In this context, the objective of this work was to develop mathematical models to predict the antioxidant capacity, total anthocyanin and total phenolic compounds of blackberry and blueberry fruits, and jaboticaba skin, using the instrumental color parameters $\left(\mathrm{L}^{*}, \mathrm{a}^{*}, \mathrm{~b}^{*}, \mathrm{C}^{*}\right.$ and $\left.\mathrm{h}^{*}\right)$ obtained from crude phenolic extracts.

\section{Materials and methods}

\subsection{Raw material}

The blackberries (Rubus sp.) and blueberries (Vaccinium sp.) were produced in the city of Barbacena, Brazil, and the jaboticabas (Plinia jaboticaba (Mart.) Kausel) were cultivated in the fruit sector of the Department of Plant Science of the Federal University of Viçosa (Viçosa, Brazil). The fruits were harvested, selected, washed and stored in a standard freezer at $-18^{\circ} \mathrm{C}$ until analysis.

\subsection{Obtaining the crude phenolic extract}

The crude phenolic extract was obtained using an ethanol solution $(70 \% \mathrm{v} / \mathrm{v})$ acidified with $\mathrm{HCl}$ to $\mathrm{pH} 2$, as the solvent (Silva, 1996). Initially, $100 \mathrm{~g}$ of each fruit and, in the case of jaboticaba, $100 \mathrm{~g}$ of skin were weighed, ground in a blender and then $1000 \mathrm{~mL}$ of solvent was added. The resultant mixture was stored under refrigeration $\left(4 \pm 2{ }^{\circ} \mathrm{C}\right)$ for $24 \mathrm{~h}$. The cooled 
blend was vacuum-filtered (Büchner funnel and Whatman no. 1 filter paper) and the extract concentrated on a rotary evaporator (IKA RV 10 digital, Staufen, Baden-Württenberg, Germany) at $40{ }^{\circ} \mathrm{C}$ until a final volume corresponding to $20 \%$ of the original volume was obtained.

\subsection{Characterization of the phenolic extracts}

Determination of total anthocyanins

Single-pH method

The total anthocyanins were quantitatively determined by the single-pH method described by Fuleki \& Francis (1968a). The reading was performed in a UV-Vis spectrophotometer (1601Pc, Shimadzu, Kyoto, Japan) at a wavelength of $535 \mathrm{~nm}$. The results were expressed as $\mathrm{mg}$ anthocyanins/mL extract.

\section{Differential $\mathrm{pH}$ method}

Measurement of the total anthocyanins by the $\mathrm{pH}$-differential method was performed according to Fuleki \& Francis (1968b). The absorbance was recorded at $535 \mathrm{~nm}$ (Shimadzu), and the results expressed as $\mathrm{mg}$ anthocyanins/mL extract.

\section{Determination of total phenolics}

The total phenolic contents of the extracts were assayed as described by Singleton \& Rossi (1965). The absorbance was measured at $760 \mathrm{~nm}$ (Shimadzu), and the results were expressed as $\mathrm{mg}$ gallic acid equivalents/mL extract (mg GAE/mL extract).

\section{Determination of antioxidant capacity}

\section{ABTS method}

For the formation of the $\mathrm{ABTS}^{\bullet+}$ radicals, the protocol described by Re et al. (1999) was adopted. Trolox was used as the standard, and the values were converted to $\mu$ mol Trolox equivalents/L extract.

\section{DPPH method}

The DPPH antioxidant capacity was evaluated according to Kim et al. (2002) with modifications. An aliquot $(0.5 \mathrm{~mL})$ of each extract was added to $3.5 \mathrm{~mL}$ of the DPPH solution and the absorbance recorded (Shimadzu) after $1 \mathrm{~h}$ of reaction. Trolox was used as a standard, and the results expressed as $\mu$ mol Trolox equivalents/L extract.

\section{FRAP method}

For the evaluation of FRAP antioxidant capacity, the FRAP reagent was prepared as detailed elsewhere (Larrauri et al., 1997). The absorbance values were converted to $\mu$ mol ferrous sulphate/mL extract, using the ferrous sulphate calibration curve.

\section{Colorimetric analysis}

The obtained phenolic extracts were characterized by the direct reading of reflectance in the CIELAB $\left(L^{*}, a^{\star}\right.$ and $\left.b^{*}\right)$ rectangular coordinate system, using a Colorquest XE colorimeter
(HunterLab, Reston, VA, USA) with D65 illuminant and $10^{\circ}$ observation angle. Chroma $\left(C^{\star}\right)$ and hue angle $\left(h^{\circ}\right)$, which represent saturation and tonality, were calculated from the $a^{\star}$ and $b^{\star}$ data, by Equations 1 and 2, respectively:

$$
\begin{aligned}
& C^{*}=\left[\left(a^{*}\right)^{2}+\left(b^{*}\right)^{2}\right]^{1 / 2} \\
& h^{\circ}=\arctan \left(b^{*} / a^{*}\right)
\end{aligned}
$$

In this color system, $L^{*}=$ the lightness coordinate; $a^{*}=$ the $\mathrm{red} /$ green coordinate, with $+a^{*}$ indicating red, and $-a^{*}$ indicating green; $b^{*}=$ the yellow/blue coordinate, with $+b^{*}$ indicating yellow, and $-b^{*}$ indicating blue; $C^{*}=$ the distance from the lightness $\left(L^{\star}\right)$ axis; and $h^{\circ}$ is expressed in degrees, with 00 being a location on the $+a^{\star}$ axis, continuing to $90^{\circ}$ for the $+b^{\star}$ axis, $180^{\circ}$ for $-a^{*}$, $270^{\circ}$ for $-b^{\star}$, and back to $360^{\circ}=0$.

\subsection{Experimental design and statistical analysis}

The experiment was performed in a completely randomised design, with three triplicate treatments (fruits, i.e., blackberry and blueberry, and jaboticaba skin) and duplicate analyses.

The results of the characterization were submitted to analysis of variance by the $\mathrm{F}$ test and the means of the treatments compared by Tukey's test. Pearson's correlation test was also conducted. The prediction model was chosen, taking into account the coefficient of determination $\mathrm{r}^{2}$, and the significance of the parameters, using multiple linear regression through the stepwise method in SAS PROC REG. All statistical analyses were computed using SAS (SAS Institute, version 9.4, Cary, NC, USA), and the level of significance was set at $p<0.05$.

\section{Results and discussion}

\subsection{Characterization of the phenolic extracts}

The extracts were characterized by the colorimetric parameters $\left(L^{\star}, a^{\star}, b^{\star}, C^{\star}, h^{\circ}\right)$, total anthocyanins, total phenolics content and antioxidant capacity. These results are presented in Table 1.

Regarding the color parameters, phenolic extracts from each fruit differed at the $5 \%$ probability level. The jaboticaba skin extract was closer to red and yellow (higher $a^{\star}$ and $b^{\star}$ ) than the others, with higher luminosity $\left(L^{*}\right)$ and saturation $\left(C^{\star}\right)$. The blueberry extract showed less tonality $\left(h^{\circ}\right)$, indicating a greater redness intensity, which indicate an increase in the content of anthocyanins (Lima et al., 2007), as verified in the anthocyanin content values, also shown in Table 1 . However, the blueberry extract showed the least saturation, implying a low color brightness.

The content of total anthocyanins by the single-pH method differed $(p<0.05)$ for the three extracts with the highest content presented by the blueberry extract, followed by jaboticaba skin and blackberry extracts (Table 1). The highest anthocyanin content of the blueberry extract was confirmed $(p<0.05)$ by the $\mathrm{pH}$-differential method. For this assay, the anthocyanin contents of the extracts of blackberry and jaboticaba skin did not differ from each other $(p>0.05)$. 
The three extracts differed from each other $(p<0.05)$ for the total phenolic content, with the jaboticaba skin extract presenting the highest content, followed by the extracts of blueberry and blackberry. The antioxidant capacity, determined by ABTS, DPPH and FRAP methods, of the jaboticaba skin extract was significantly higher when compared with the other extracts $(p<0.05)$. However, the extracts of blackberry and blueberry did not differ among themselves $(p>0.05)$ for the three methods used.

In addition to anthocyanins, jaboticaba skin has high levels of tannins, phenolic acids (ellagic acid) and other flavonoids (rutin and quercetin) (Silva et al., 2013). Furthermore, the phenolic compounds are concentrated in the skin of fruits and leaves (Paes et al., 2014). To obtain the extract of jaboticaba, only the skins were used, unlike the extracts of blueberry and blackberry, where the whole fruit was extracted.

Jaboticaba skin has a higher vitamin $\mathrm{C}$ content than the fruits of blackberry and blueberry. Approximate vitamin $\mathrm{C}$ values found in the literature are $21 \mathrm{mg} / 100 \mathrm{~g}$ for blackberry (Kaume et al., 2012), 190 mg/100 g for blueberry (Barcia et al., 2010), and $250 \mathrm{mg} / 100 \mathrm{~g}$ for jaboticaba skin (Lima et al., 2011). According to Oliveira et al., (2017), ascorbic acid influences the analyses of antioxidant capacity (ABTS, DPPH and FRAP). Probably, among other factors, this was the main reason why jaboticaba skin exhibited a higher antioxidant capacity than the other fruits.

\subsection{Correlation between the levels of total phenolics, anthocyanins and antioxidant capacity with colorimetric coordinates}

Table 2 presents the correlation results between the parameters of color, total phenolics, anthocyanins and antioxidant capacity, obtained for the crude phenolic extracts.

The $L^{\star}, a^{\star}, b^{\star}$ and $C^{\star}$ parameters significantly correlated at the $5 \%$ probability level with the results obtained for anthocyanins (pH-differential method), total phenolic content and for all antioxidant capacity methods (Table 2), which are the most important correlations in the context of the present work. It shows a high probability of a mathematical model to predict the content of anthocyanins, phenolic compounds and antioxidant capacity using these colorimetric parameters. The $h^{\circ}$ showed a strong correlation $(\mathrm{p}<0.01)$ for the two approaches used to quantify total anthocyanin content (single-pH method: $r=-0.85$ and pH-differential method: $r=-0.86$ ) (Table 2).

Table 1. Colorimetric parameters $\left(\mathrm{L}^{\star}, \mathrm{a}^{\star}, \mathrm{b}^{\star}, \mathrm{C}^{\star}\right.$ and $\left.\mathrm{h}^{\star}\right)$, total phenolic, anthocyanin contents and antioxidant capacity of the crude phenolic extract obtained from blackberry, blueberry and jaboticaba skin.

\begin{tabular}{|c|c|c|c|}
\hline PARAMETER & BLACKBERRY & BLUEBERRY & JABOTICABA SKIN \\
\hline $\mathbf{L}^{*}$ & $31.117 \pm 0.38^{\mathrm{a}}$ & $27.18 \pm 0.16^{c}$ & $33.32 \pm 0.97^{b}$ \\
\hline$a^{*}$ & $19.41 \pm 1.31^{\mathrm{b}}$ & $3.87 \pm 1.22^{c}$ & $28.57 \pm 2.56^{\mathrm{a}}$ \\
\hline $\mathbf{b}^{*}$ & $6.41 \pm 0.58^{\mathrm{b}}$ & $0.10 \pm 0.35^{\mathrm{c}}$ & $10.43 \pm 1.68^{\mathrm{a}}$ \\
\hline $\mathbf{C}^{*}$ & $20.44 \pm 1.42^{\mathrm{b}}$ & $3.88 \pm 1.23^{c}$ & $30.42 \pm 2.98^{\mathrm{a}}$ \\
\hline $\mathbf{h}^{*}$ & $0.32 \pm 0.01^{\mathrm{a}}$ & $0.01 \pm 0.07^{\mathrm{b}}$ & $0.35 \pm 0.02^{\mathrm{a}}$ \\
\hline Total anthocyanins (single pH) & $181.52 \pm 13.59^{c}$ & $555.16 \pm 53.41^{\mathrm{a}}$ & $354.72 \pm 42.29^{\mathrm{b}}$ \\
\hline Total anthocyanins (differential pH) & $100.04 \pm 12.90^{\mathrm{b}}$ & $403.91 \pm 57.41^{\mathrm{a}}$ & $184.18 \pm 8.02^{\mathrm{b}}$ \\
\hline Total phenolics & $975.21 \pm 35.16^{c}$ & $1437.23 \pm 110.67^{\mathrm{b}}$ & $4548.93 \pm 211.51^{\mathrm{a}}$ \\
\hline Antioxidant capacity (ABTS) & $51.94 \pm 4.58^{\mathrm{b}}$ & $47.23 \pm 3.82^{\mathrm{b}}$ & $410.89 \pm 28.8^{\mathrm{a}}$ \\
\hline Antioxidant capacity (DPPH) & $40.25 \pm 9.31^{\mathrm{b}}$ & $21.78 \pm 6.40^{\mathrm{b}}$ & $355.63 \pm 53.07^{\mathrm{a}}$ \\
\hline Antioxidant capacity (FRAP) & $99.18 \pm 19.71^{\mathrm{b}}$ & $101.26 \pm 41.00^{\mathrm{b}}$ & $906.76 \pm 67.88^{\mathrm{a}}$ \\
\hline
\end{tabular}

Results of total anthocyanin contents (single $\mathrm{pH}$ and differential $\mathrm{pH}$ ) were expressed in $\mathrm{mg}$ of anthocyanin/L extract, total phenolic content in mg equivalent of gallic acid/L extract, ABTS and DPPH in $\mu \mathrm{M}$ Trolox/L extract and FRAP in $\mu \mathrm{M}$ ferrous sulfate/L extract. Values in mean \pm standard deviation $(\mathrm{SD})$, $\mathrm{n}=3$. Significance $(\mathrm{P}<0.05)$ : means followed by at least one letter in the row do not differ by Tukey test.

Table 2. Pearson's correlation (r) between the parameters studied for the crude phenolic extract.

\begin{tabular}{|c|c|c|c|c|c|c|c|c|c|c|c|}
\hline & $\mathrm{L}$ & $\mathrm{a}$ & $\mathrm{b}$ & $\mathrm{C}$ & $\mathrm{h}$ & AntTsin. & AntTdif. & Phenolics & ABTS & DPPH & FRAP \\
\hline $\mathbf{L}$ & 1.000 & $0.998^{\star *}$ & $0.999^{\star *}$ & $0.998^{\star *}$ & $0.936^{\star *}$ & -0.665 & $-0.773^{*}$ & $0.676^{*}$ & $0.752^{*}$ & $0.761^{\star}$ & $0.739^{*}$ \\
\hline $\mathbf{a}$ & & 1.000 & $0.997^{\star \star}$ & $1.000^{* *}$ & $0.941^{\star *}$ & -0.655 & $-0.765^{\star}$ & $0.691^{\star}$ & $0.771^{\star}$ & $0.780^{\star}$ & $0.757^{\star}$ \\
\hline $\mathbf{b}$ & & & 1.000 & $0.998^{\star *}$ & $0.928^{\star *}$ & -0.640 & $-0.750^{*}$ & $0.699^{*}$ & $0.772^{\star}$ & $0.778^{\star}$ & $0.758^{\star}$ \\
\hline C & & & & 1.000 & $0.939^{\star *}$ & -0.651 & $-0.761^{\star}$ & $0.695^{\star}$ & $0.773^{\star}$ & $0.782^{\star}$ & $0.759^{*}$ \\
\hline $\mathbf{h}$ & & & & & 1.000 & $-0.849^{* *}$ & $-0.862^{\star *}$ & 0.440 & 0.546 & 0.566 & 0.524 \\
\hline AntTsin. & & & & & & 1.000 & $0.928^{\star *}$ & 0.082 & -0.042 & -0.073 & -0.022 \\
\hline AntTdif. & & & & & & & 1.000 & -0.129 & -0.252 & -0.289 & -0.247 \\
\hline Phenolics & & & & & & & & 1.000 & $0.990^{* *}$ & $0.979^{\star *}$ & $0.989^{* *}$ \\
\hline ABTS & & & & & & & & & 1.000 & $0.995^{\star *}$ & $0.998^{\star *}$ \\
\hline DPPH & & & & & & & & & & 1.000 & $0.993^{\star *}$ \\
\hline FRAP & & & & & & & & & & & 1.000 \\
\hline
\end{tabular}

AntTsin. $=$ Total Anthocyanin content by the single $\mathrm{pH}$ method; AntTdif. $=$ Total Anthocyanin content by the differential $\mathrm{pH}$ method. Correlation was established by the Pearson method. ${ }^{*}$ indicates significant correlation at $5 \%$ probability; ${ }^{* *}$ indicates significant correlation at $1 \%$ probability and the others are non-significant. 
Correlations between color parameters and total anthocyanin content were, in all cases, negative, demonstrating that as the anthocyanin content increases, the color parameters decrease. Similarly, Cesa et al. (2017) also found a negative correlation between the anthocyanin content of blueberry extracts and color parameters, mainly with the $h^{\circ}$ parameter. In addition, Lima et al. (2007) reported a negative correlation between the color parameters $L^{\star}, b^{\star}, C^{\star}$ and $h^{\circ}$ (i.e., except $a^{\star}$ ) and the content of anthocyanins in acerola pulps (Sariburun et al., 2010).

Finally, the phenolic compounds confer high antioxidant capacity to the fruits, showing a correlation between this parameter and the total phenolic content (Ferrari et al., 2012; Sariburun et al., 2010). As it is shown in Table 2, for the crude extracts, total phenolic content was strongly correlated $(p<0.01)$ with the three methods used to evaluate the antioxidant capacity. In other words, the high total content of phenolic compounds was related to the high antioxidant capacity, and, in the fruits studied, the antioxidant capacity was mainly due to the phenolic compounds.

\subsection{Mathematical models of prediction of extracts obtained}

The equations obtained for the predictions are presented in Table 3, wherein, it is verified that it was possible to achieve a mathematical model to predict all the dependent variables studied.

For quantification of total anthocyanins, the prediction equation for the single-pH method showed $\mathrm{r}^{2}=0.99$. For the $\mathrm{pH}$-differential method, the best equation had an $\mathrm{r}^{2}=0.74$. Both methods express the actual fraction of anthocyanins. However, some researchers, such as Fuleki \& Francis (1968b), Wrolstad (1976), Jackman \& Smith (1996) and Teixeira et al. (2008), concluded that there is a difference between the single-pH and $\mathrm{pH}$-differential methods in the quantification of anthocyanins when there are interferents in the extract, such as degradation products of the anthocyanins themselves, tannins and sulphur compounds. Although these compounds do not present absorption at the wavelength used, they contribute to the broadening of the spectrum, thereby justifying their interfering activity (Teixeira et al., 2008). In such instances, the use of the $\mathrm{pH}$-differential method must be chosen, as the spectral characteristics of these interferents are not altered as a function of the $\mathrm{pH}$ of the medium (Francis, 1982), and when the reading difference is made at $\mathrm{pH} 1.0$ and 4.5 , the value of the interferents is eliminated. Therefore, it can be observed from the results presented that the single-pH method obtained a higher correlation coefficient than the $\mathrm{pH}$-differential method, which takes into account the interferences.

For the total phenolic content and antioxidant capacities determined by ABTS, DPPH and FRAP methods, the determination coefficients $\left(\mathrm{r}^{2}\right)$ for the equations were $0.86,0.99,0.97$ and 0.98 , respectively (Table 3 ).

A mathematical prediction model was obtained for the total anthocyanin content, which are compounds of extreme relevance in the fruits studied. In addition, more complex and time-consuming analyses, such as the analysis of total phenolic compounds content and antioxidant capacity, provided mathematical prediction models with high $\mathrm{r}^{2}$.

Recently, research on predicting the contents of total phenolics, anthocyanins and the antioxidant capacity of 13 fruits and vegetables, using colorimetric coordinates, was carried out (Vieira et al., 2019). Equations with $\mathrm{r}^{2}$ of 0.99 to predict the content of total anthocyanins were obtained, however, they demonstrated that it was not possible to predict the content of total phenolics and the antioxidant capacity through colorimetry. The reason may be because they used a larger variety of fruits and vegetables, and the prediction was only studied for crude, diluted or non-diluted phenolic extracts (Vieira et al., 2019).

Using infrared spectroscopy, Oliveira et al. (2018) performed a prediction analysis for anthocyanins and total phenolics content and antioxidant capacity in crude phenolic extracts of violet grape and purple cabbage. For the violet grape, a mathematical prediction model was found only for antioxidant capacity by the DPPH method $\left(r^{2}=0.99\right)$. For purple cabbage, a three-ban mathematical model to predict the anthocyanins, phenolics and antioxidant capacity was obtained, with $\mathrm{r}^{2}=0.99$ for all variables, however the results were obtained by multivariate analysis and then more complex equations were obtained.

In addition, other studies have also predicted the antioxidant capacity, the amount of phenolic compounds and anthocyanins, and the nutritional quality of fruits and vegetables. Pace et al. (2013) correlated the antioxidant activity and phenolic compounds of carrots, of different varieties, with colorimetric parameters, obtaining mathematical models of prediction with low $\mathrm{r}^{2}$, around 0.5. Mariani et al. (2015) investigated the prediction of anthocyanins content in jaboticaba, using near-infrared spectroscopy, a statistical method called the least squares partial interval and a genetic algorithm. They obtained a correlation between the measured and

Table 3. Multiple linear regression equations, adjusted for prediction of total phenolic, anthocyanin contents and antioxidant capacity of blackberry, blueberry and jaboticaba skin using colorimetric parameters.

\begin{tabular}{ccc}
\hline Parameters & Equation & $\mathrm{R}^{2}$ \\
\hline Total anthocyanins (single $\mathrm{pH})$ & $\mathrm{Ant}_{\text {single }}=15269-555.03 \mathrm{~L}^{*}-553.3^{\mathrm{a} *}+651.19 \mathrm{C}^{*}-1209.72 \mathrm{~h}^{*}$ & 0.9969 \\
Total anthocyanins (differential $\mathrm{pH})$ & $\mathrm{Ant}_{\text {differential }}=391.78-720 \mathrm{~h}^{*}$ & 0.7438 \\
Total phenolica & $\mathrm{CF}=278378-10212 \mathrm{~L}^{*}+6344.09 \mathrm{~b}^{*}$ & 0.8613 \\
ABTS & $\mathrm{CA}_{\mathrm{ABTS}}=15945-599.78 \mathrm{~L}^{*}+168.99 \mathrm{~b}^{*}+103.49 \mathrm{C}^{*}-1328.17 \mathrm{~h}^{*}$ & 0.9886 \\
DPPH & $\mathrm{CA}_{\mathrm{DPPH}}=9106.18-349.75 \mathrm{~L}^{*}+111.64 \mathrm{C}^{*}-1429.72 \mathrm{~h}^{*}$ & 0.9697 \\
FRAP & $\mathrm{CAF}_{\mathrm{FRAP}}=21036-807.13 \mathrm{~L}^{*}+266.85 \mathrm{C}^{*}-3925.46 \mathrm{~h}^{*}$ & 0.9805 \\
\hline
\end{tabular}

The Ant $\mathrm{T}_{\text {single }}\left(\right.$ Total Anthocyanin content by single $\mathrm{pH}$ method) and $\mathrm{Ant}_{\text {differential }}($ Total Anthocyanin content by the differential $\mathrm{pH}$ method $)=\mathrm{mg}$ anthocyanin/L extract; $\mathrm{CF}=\mathrm{mg}$ gallic acid equivalent $/ \mathrm{L}$ extract; $\mathrm{CA}=\mu \mathrm{M}$ Trolox $/ \mathrm{L}$ extract; and $\mathrm{CAF}=\mu \mathrm{M}$ ferrous sulfate $/ \mathrm{L}$ extract and $\mathrm{R}^{2}=$ determination coefficient. 
predicted total anthocyanins content of between 0.65 and 0.89 . Lou et al. (2012) conducted a non-destructive prediction analysis of blackberry fruit at different stages of maturation, using predicted chlorophyll fluorescence parameters and red, green and blue intensity values. The dependent variables were flavonoid content $\left(r^{2}=0.97\right)$, content of phenolic compounds $\left(r^{2}=0.93\right)$, ABTS $\left(r^{2}=0.93\right)$ and DPPH $\left(r^{2}=0.95\right)$.

The current work shows the importance of the prediction in the search for cost-effective and time efficiency approaches in the analysis of bioactive compounds in fruit. Besides, the originality of the present work, to obtain linear mathematical models that are both accessible and easy to use by industry and laboratories of analysis of bioactive compounds, is demonstrated.

\section{Conclusion}

There were significant and high correlations between the color parameters and all the analyses performed in the crude phenolic extracts from blueberry, blackberry and jaboticaba skin, resulting in multiple linear regression equations with high $\mathrm{r}^{2}$ for the prediction of total anthocyanins $\left(\mathrm{r}^{2}=0.99\right)$, total phenolics $\left(\mathrm{r}^{2}=0.86\right)$ and antioxidant capacity determined by three methods, ABTS $\left(r^{2}=0.99\right)$, DPPH $\left(r^{2}=0.97\right)$ and FRAP $\left(r^{2}=0.98\right)$.

Thus, the prediction of total phenolics, anthocyanins and antioxidant capacity of the three fruits (blackberry, blueberry and jaboticaba skin), using the colorimetric parameters, is feasible and highly promising from a cost and time perspective.

\section{Acknowledgements}

This research was supported by the Conselho Nacional de Desenvolvimento Científico e Tecnológico (CNPq).

\section{References}

Barba, F. J., Esteve, M. J., \& Frigola, A. (2013). Physicochemical and nutritional characteristics of blueberry juice after high pressure processing. Food Research International, 50(2), 545-549. http:// dx.doi.org/10.1016/j.foodres.2011.02.038.

Barcia, M. T., Jacques, A. C., Pertuzatti, P. B., \& Zambiazi, R. C. (2010). Determinação de ácido ascórbico e tocoferóis em frutas por CLAE. Ciências Agrarias, 31(2), 381-390. http://dx.doi.org/10.5433/16790359.2010v31n2p381.

Bowen-Forbes, C. S., Zhang, Y., \& Nair, M. G. (2010). Anthocyanin content, antioxidant, anti-inflammatory and anticancer properties of blackberry and raspberry fruits. Journal of Food Composition and Analysis, 23(6), 554-560. http://dx.doi.org/10.1016/j.jfca.2009.08.012.

Cesa, S., Carradori, S., Bellagamba, G., Locatelli, M., Casadei, M. A., Masci, A., \& Paolicelli, P. (2017). Evaluation of processing effects on anthocyanin content and colour modifications of blueberry (Vaccinium spp.) extracts: comparison between HPLC-DAD and CIELAB analyses. Food Chemistry, 232, 114-123. http://dx.doi. org/10.1016/j.foodchem.2017.03.153. PMid:28490054.

Ekici, L., Simsek, Z., Ozturk, I., Sagdic, O., \& Yetim, H. (2014). Effects of temperature, time, and $\mathrm{pH}$ on the stability of anthocyanin extracts: prediction of total anthocyanin content using nonlinear models. Food Analytical Methods, 7(6), 1328-1336. http://dx.doi. org/10.1007/s12161-013-9753-y.
Ferrari, C. C., Germer, S. P. M., \& de Aguirre, J. M. (2012). Effects of spray-drying conditions on the physicochemical properties of blackberry powder. Drying Technology, 30(2), 154-163. http://dx.doi. org/10.1080/07373937.2011.628429.

Francis, F. J. (1982). Analysis of anthocyanins in foods. In P. Markakis (Ed.), Anthocyanins as food colors (pp. 181-207). New York: Academic Press. http://dx.doi.org/10.1016/B978-0-12-472550-8.50011-1.

Fuleki, T., \& Francis, F. J. (1968a). Quantative methods for analysis. 1. Extraction and determination of total anthocyanin in cranberries. Journal of Food Science, 33(1), 72-77. http://dx.doi. org/10.1111/j.1365-2621.1968.tb00887.x.

Fuleki, T., \& Francis, F. J. (1968b). Quantitative methods for anthocyanins. 2. Determination of total anthocyanin and degradation index for cranberry juice. Journal of Food Science, 33(1), 78-83. http://dx.doi. org/10.1111/j.1365-2621.1968.tb00888.x.

Hosu, A., Cristea, V. M., \& Cimpoiu, C. (2014). Analysis of total phenolic, flavonoids, anthocyanins and tannins content in Romanian red wines: Prediction of antioxidant activities and classification of wines using artificial neural networks. Food Chemistry, 150, 113-118. http://dx.doi.org/10.1016/j.foodchem.2013.10.153. PMid:24360427.

Jackman, R. L., \& Smith, J. L. (1996). Anthocyanins and betalains. In G. A. F. Hendry \& J. D. Houghton (Eds.), Natural food colorants (2nd ed., pp. 245-309). London: Chapman \& Hall. http://dx.doi. org/10.1007/978-1-4615-2155-6_8.

Kaume, L., Howard, L. R., \& Devareddy, L. (2012). The blackberry fruit: A review on its composition and chemistry, metabolism and bioavailability, and health benefits. Journal of Agricultural and Food Chemistry, 60(23), 5716-5727. http://dx.doi.org/10.1021/jf203318p. PMid:22082199.

Kim, D.-O., Lee, K. W., Lee, H. J., \& Lee, C. Y. (2002). Vitamin C Equivalent Antioxidant Capacity (VCEAC) of phenolic phytochemicals. Journal of Agricultural and Food Chemistry, 50(13), 3713-3717. http://dx.doi. org/10.1021/jf020071c. PMid:12059148.

Larrauri, J. A., Rupérez, P., \& Saura-Calixto, F. (1997). Effect of drying temperature on the stability of polyphenols and antioxidant activity of red grape pomace peels. Journal of Agricultural and Food Chemistry, 45(4), 1390-1393. http://dx.doi.org/10.1021/jf960282f.

Lima, A. D. J. B., Corrêa, A. D., Saczk, A. A., Martins, M. P., \& Castilho, R. O. (2011). Anthocyanins, pigment stability and antioxidant activity in jabuticaba [Myrciaria cauliflora (Mart.) O. Berg]. Revista Brasileira de Fruticultura, 33(3), 877-887. http://dx.doi.org/10.1590/ S0100-29452011000300023.

Lima, V. L. A. G., Mélo, E. A., \& Guerra, N. B. (2007). Correlação entre o teor de antocianinas e caracterização cromática de polpas de diferentes genótipos de aceroleira. Brazilian Journal of Food Technology, 10, 51-55.

Lou, H., Hu, Y., Zhang, L., Sun, P., \& Lu, H. (2012). Nondestructive evaluation of the changes of total flavonoid, total phenols, ABTS and DPPH radical scavenging activities, and sugars during mulberry (Morus alba L.) fruits development by chlorophyll fluorescence and RGB intensity values. Lebensmittel-Wissenschaft + Technologie, 47(1), 19-24. http://dx.doi.org/10.1016/j.lwt.2012.01.008.

Mariani, N. C., Teixeira, G. H. A., Lima, K. M., Morgenstern, T. B., Nardini, V., \& Cunha, L. Jr. (2015). NIRS and iSPA-PLS for predicting total anthocyanin content in jaboticaba fruit. Food Chemistry, 174, 643-648. http://dx.doi.org/10.1016/j.foodchem.2014.11.008. PMid:25529731.

Oliveira, I. R. N., Roque, J. V., Maia, M. P., Stringheta, P. C., \& Teófilo, R. F. (2018). New strategy for determination of anthocyanins, polyphenols and antioxidant capacity of Brassica oleracea liquid extract using infrared spectroscopies and multivariate regression. Spectrochimica 
Acta. Part A: Molecular and Biomolecular Spectroscopy, 194, 172180. http://dx.doi.org/10.1016/j.saa.2018.01.006. PMid:29331819.

Oliveira, I. R. N., Teófilo, R. F., Oliveira, E. B., Ramos, A. M., Barros, F. A. R., Maia, M. P., \& Stringheta, P. C. (2017). Evaluation of potential interfering agents on in vitro methods for the determination of the antioxidant capacity in anthocyanin extracts. International Journal of Food Science \& Technology, 52(2), 511-518. http://dx.doi. org/10.1111/ijfs.13307.

Pace, B., Cefola, M., Renna, F., Renna, M., Serio, F., \& Attolico, G. (2013). Multiple regression models and Computer Vision Systems to predict antioxidant activity and total phenols in pigmented carrots. Journal of Food Engineering, 117(1), 74-81. http://dx.doi. org/10.1016/j.jfoodeng.2013.02.005.

Paes, J., Dotta, R., Barbero, G. F., \& Martínez, J. (2014). Extraction of phenolic compounds and anthocyanins from blueberry (Vaccinium myrtillus L.) residues using supercritical $\mathrm{CO}_{2}$ and pressurized liquids. The Journal of Supercritical Fluids, 95, 8-16. http://dx.doi. org/10.1016/j.supflu.2014.07.025.

Queiroz, A. J. M. (2015). Evolução das antocianinas, atividade antioxidante e parâmetros de cor no Vinho do Porto ao longo do seu envelhecimento. Porto: Universidade do Porto.

Re, R., Pellegrini, N., Proteggente, A., Pannala, A., Yang, M., \& RiceEvans, C. (1999). Antioxidant activity applying an improved ABTS radical cation decolorization assay. Free Radical Biology \& Medicine, 26(9-10), 1231-1237. http://dx.doi.org/10.1016/S0891-5849(98)003153. PMid:10381194.

Rocha, W. S., Lopes, R. M., Silva, D. B., Vieira, R. F., Silva, J. P., \& Agostini-Costa, T. S. (2011). Compostos fenólicos totais e taninos condensados em frutas nativas do cerrado. Revista Brasileira de Fruticultura, 33(4), 1215-1221. http://dx.doi.org/10.1590/S010029452011000400021.

Sariburun, E., Şahin, S., Demir, C., Türkben, C., \& Uylaşer, V. (2010). Phenolic content and antioxidant activity of raspberry and blackberry cultivars. Journal of Food Science, 75(4), 328-335. http://dx.doi. org/10.1111/j.1750-3841.2010.01571.x. PMid:20546390.

Silva, M. C., Souza, V. B., Thomazini, M., Silva, E. R., Smaniotto, T., Carvalho, R. A., Genovese, M. I., \& Favaro-Trindade, C. S. (2014). Use of the jabuticaba (Myrciaria cauliflora) depulping residue toproduce a natural pigment powder with functional properties. Lebensmittel-Wissenschaft + Technologie, 55(1), 203-209. http:// dx.doi.org/10.1016/j.lwt.2013.08.026.

Silva, P. I., Stringheta, P. C., Teófilo, R. F., \& Oliveira, I. R. N. (2013). Parameter optimization for spray-drying microencapsulation of jaboticaba (Myrciaria jaboticaba) peel extracts using simultaneous analysis of responses. Journal of Food Engineering, 117(4), 538-544. http://dx.doi.org/10.1016/j.jfoodeng.2012.08.039.

Silva, S. R. (1996). Extração e estabilidade de pigmentos antociânicos de frutos de maria-pretinha (Solanum americanum, mil.). Viçosa: Universidade Federal de Viçosa.

Singleton, V. L., \& Rossi, J. A. J. (1965). Colorimetry of total phenolics with phosmolybdic-phosphotungstic acid reagents. American Journal of Enology and Viticulture, 16, 144-158. Retrieved from http://scihub.cc/http://www.ajevonline.org/content/16/3/144

Sousa, M. S. B., Vieira, L. M., \& Lima, A. (2011). Fenólicos totais e capacidade antioxidante in vitro de resíduos de polpas de frutas tropicais. Brazilian Journal of Food Technology, 14(03), 202-210. http://dx.doi.org/10.4260/BJFT2011140300024.

Teixeira, L. N., Stringheta, P. C., \& Oliveira, F. A. (2008). Comparação de métodos para quantificação de antocianinas. Revista Ceres, 55(4), 297-304.

Vieira, L. M., Marinho, L. M. G., Rocha, J., Barros, F. A. R., \& Stringheta, P. C. (2019). Chromatic analysis for predicting anthocyanin content in fruits and vegetables. Food Science and Technology, 39(2), 415422. http://dx.doi.org/10.1590/fst.32517.

Wrolstad, R. E. (1976). Colors and pigment analysis in fruit products. Coravallis: Oregon Agricultural Experimental Station. 